\title{
Cage Occupancy of Hydrogen in Carbon Dioxide, Ethane, Cyclopropane, and Propane Hydrates
}

\author{
Takeshi Sugahara, Hiroki Mori, Jun Sakamoto, Shunsuke Hashimoto, Kyohei Ogata and Kazunari \\ Ohgaki*
}

Division of Chemical Engineering, Graduate School of Engineering Science, Osaka University, 1-3, Machikaneyama,
Toyonaka, Osaka 560-8531, Japan

\begin{abstract}
We have already reported the cage unoccupancy of hydrogen in the $\mathrm{CO}_{2}$ hydrate from the Raman spectroscopic analysis and the thermodynamic analysis using Soave - Redlich - Kwong equation of state. On the other hand, at the low temperatures, Kim and Lee (Journal of American Chemical Society, vol. 127, pp. 9996-9997, Jul. 2005) claimed that hydrogen is enclathrated in the $\mathrm{CO}_{2}$ hydrate. In the present study, the cage unoccupancy of hydrogen in the $\mathrm{CO}_{2}$ hydrate was reconfirmed clearly by in situ Raman spectroscopy for single crystal of gas hydrates. Isothermal phase equilibria (pressure - composition) and Raman spectra for three ternary systems of hydrogen + hydrocarbon (ethane, cyclopropane, propane) + water with same experimental procedures as hydrogen $+\mathrm{CO}_{2}+$ water system were measured at $276.1 \mathrm{~K}$ in the pressure range up to $5 \mathrm{MPa}$. In addition, the released gas from hydrates was analyzed to confirm the occupancy or unoccupancy of hydrogen at the temperature. All analyses arrive at the single conclusion that hydrogen is enclathrated in only propane hydrate under the present experimental conditions.
\end{abstract}

\section{INTRODUCTION}

Gas hydrates are stabilized by guest species in the cavity of cages composed of the hydrogen-bonded water molecules. Three types of hydrate cages are well-known, pentagonal dodecahedron $\left(5^{12}\right.$, Small-cage (hereafter, S-cage)), tetrakaidecahedron $\left(5^{12} 6^{2}\right.$, Middle-cage (M-cage) $)$ and hexakaidecahedron $\left(5^{12} 6^{4}\right.$, Large-cage (L-cage)). The combination of two S-cages and six M-cages builds the structure-I (sI) hydrate lattice (cubic, $P m 3 n$ ), and that of sixteen S-cages and eight L-cages builds the structure-II (s-II) hydrate lattice (cubic, $F d 3 m$ ). Gas hydrates have potential for versatile applications, due to some characteristic properties of gas storage, chemical stability, lightness and so on.

The separation, storage, and transportation of $\mathrm{H}_{2}$ are one of the most important techniques for developing a new society sustained by $\mathrm{H}_{2}$ energies. The generation of pure s-II $\mathrm{H}_{2}$ hydrate requires a high pressure of $100-360 \mathrm{MPa}$ at ambient temperatures [1]. The hydrate cages are multiple occupied with a cluster of two $\mathrm{H}_{2}$ molecules in the $\mathrm{S}$-cage and four $\mathrm{H}_{2}$ molecules in the L-cage, respectively [2]. The mixed-gas hydrate systems containing $\mathrm{H}_{2}$ and suitable additives enable us to perform the $\mathrm{H}_{2}$ storage at much lower pressure conditions than the pure $\mathrm{H}_{2}$ hydrate. Tetrahydrofuran (hereafter, THF) is the most familiar of such additives [3-8]. In addition, quaternary ammonium salts $[6,9-12]$, cyclic hydrocarbons [13] and so on have been reported.

In our previous study, phase equilibria containing gas hydrate, aqueous and gas phases for the ternary system of $\mathrm{H}_{2}$ $+\mathrm{CO}_{2}+$ water have been investigated at $274.3-281.9 \mathrm{~K}$ up to $10 \mathrm{MPa}$ [14]. The s-I $\mathrm{CO}_{2}$ hydrate generated from the mixture cannot entrap the $\mathrm{H}_{2}$ molecule. The additional

*Address correspondence to this author at the Division of Chemical Engineering, Graduate School of Engineering Science, Osaka University, 1-3, Machikaneyama, Toyonaka, Osaka 560-8531, Japan; Fax: +81-6-68506290, E-mail: ohgaki@cheng.es.osaka-u.ac.jp
Raman spectroscopic result also supports it. However, the intensity of Raman spectra indicated in our previous paper [14] has been somewhat weak due to the effect of the combination between window material and wavelength of laser. Such weak peak may lead to confusion and misinterpretation about the results of $\mathrm{H}_{2}$ unoccupancy in the $\mathrm{CO}_{2}$ hydrate. On the other hand, at the low temperatures of 120-180 K, Kim and Lee [15] claimed that $\mathrm{H}_{2}$ is enclathrated in $\mathrm{CO}_{2}$ hydrate, which contradicts the results at the relatively high temperatures of 274.3-281.9 $\mathrm{K}$ in our previous paper. It is necessary to reconfirm our results.

Zhang, Chen, Ma, Yang, and Guo [16] and Klauda and Sandler [17] have reported that $\mathrm{H}_{2}$ may partially fill the hydrate cages with other guest species. Recently, Skiba, Larionov, Manakov, Kolesov, and Kosyakov [18] have reported that the $\mathrm{H}_{2}$ molecules are not detected in the hydrate generated from $\mathrm{H}_{2}+\mathrm{CH}_{4}$ mixtures at a pressure up to 250 $\mathrm{MPa}$. The information for the cage occupancies of guest species and the thermodynamic stability of mixed gas hydrate for $\mathrm{H}_{2}+$ other gas mixed hydrate systems, however, are insufficient.

In the present study, at first, the cage unoccupancy of $\mathrm{H}_{2}$ in the $\mathrm{CO}_{2}$ hydrate was reconfirmed clearly by in situ Raman spectroscopy for single crystal of gas hydrates. Subsequently, isothermal phase equilibria (pressure - composition) and Raman spectra for three ternary systems of $\mathrm{H}_{2}+$ hydrocarbon (ethane, cyclopropane, propane) + water with same experimental procedures as $\mathrm{H}_{2}+\mathrm{CO}_{2}+$ water system were measured at $276.1 \mathrm{~K}$ in the pressure range up to $5 \mathrm{MPa}$.

\section{EXPERIMENTAL APPARATUS}

The experimental apparatus is the same as the previous one [14]. The inner volume and maximum working pressure of the high-pressure cell were $150 \mathrm{~cm}^{3}$ and $10 \mathrm{MPa}$, respectively. The cell had a set of windows for visually observing the phase behavior. All parts of the high-pressure cell were immersed in a temperature-controlled water bath. The con- 
tents were agitated using an up-and-down mixing bar driven by an exterior permanent magnetic ring.

The high-pressure optical cell for the Raman spectroscopic analyses had a pair of quartz (highly pure) windows on both the upper and lower sides. This high-pressure optical cell is the same as previous one [14] except for the window material. In our previous study [14], the ordinary sapphire windows were used. However, very intensive and broad fluorescence peak derived from the impurities of sapphire window was overlapped with the $\mathrm{H}_{2}$ vibration peaks. We have been forced to use He-Ne laser (generation power is 35 $\mathrm{mW}$ ) near at hand. Nevertheless, the undesirable peaks are detected as shown in Fig. (1a). To get the information of $\mathrm{H}_{2}$ occupancy in greater detail, in the present study, the windows made of quartz (highly pure), which do not have bothering peaks in a relevant wavenumber range around 4100 $\mathrm{cm}^{-1}$ as shown in Fig. (1b and 1c), were adopted. The thermostated water was circulated constantly in the exterior jacket of the high-pressure optical cell. A ruby ball was enclosed into the high-pressure optical cell. The contents were agitated by the ruby ball, which is rolled around by the vibration of vibrator from outside.

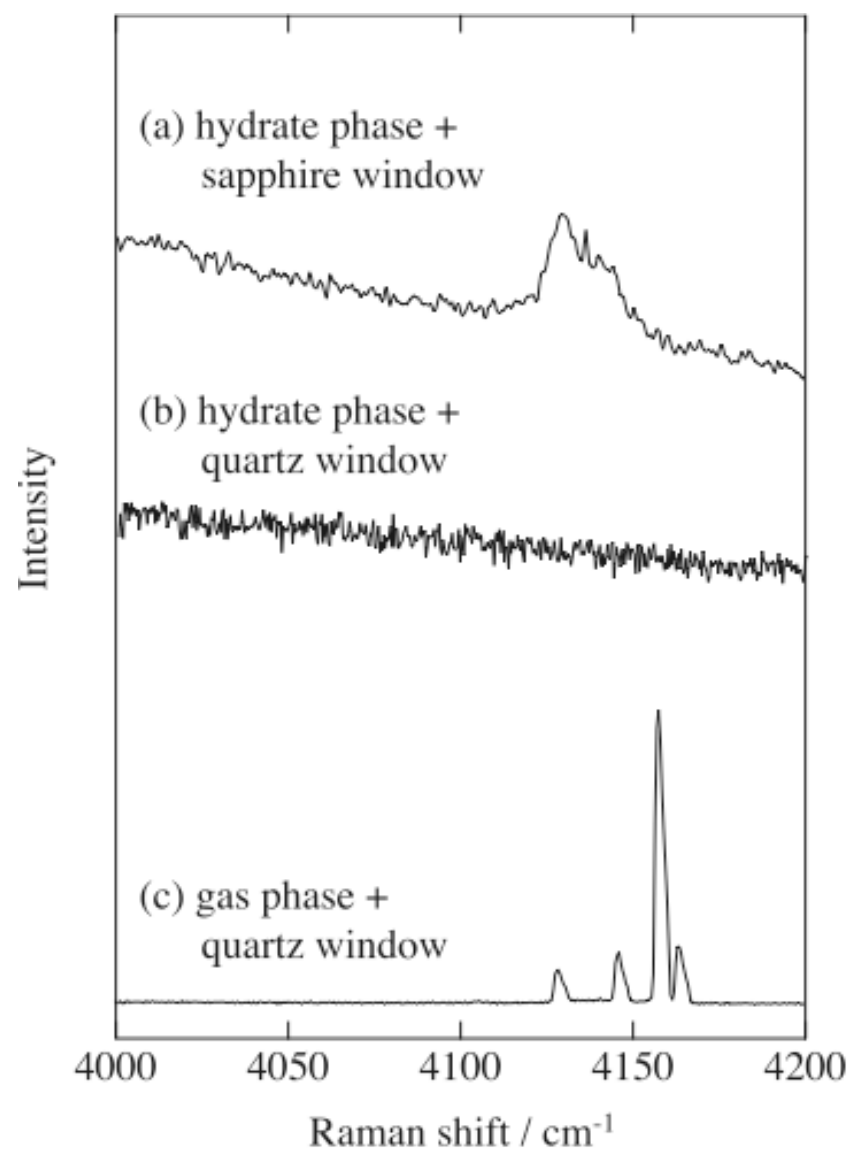

Fig. (1). Raman spectra around $4100 \mathrm{~cm}^{-1}$ in the hydrate generated from $\mathrm{H}_{2}+\mathrm{CO}_{2}+$ water mixed system (a) with sapphire windows by use of He-Ne laser (15.2 MPa and 274.6 K) [14], and (b) with quartz windows by use of $\mathrm{Ar}$ ion laser (11.2 MPa and 276.5 K). The spectrum (c) of gas phase was obtained by use of quartz window and $\mathrm{Ar}$ ion laser at 11.2 $\mathrm{MPa}$ and $276.5 \mathrm{~K}$.

The system temperature was measured within an uncertainty of $0.02 \mathrm{~K}$ using a thermistor probe (Takara D-632), which was inserted into a hole in the cell wall. The probe was calibrated with a Pt resistance thermometer defined by ITS-90. The system pressure was measured by a pressure gage (Valcom VPRT) calibrated by RUSKA quartz Bourdon tube gage (Direct Reading Pressure Gage, series 6000) with an estimated maximum uncertainty of $0.01 \mathrm{MPa}$.

\section{Materials}

Research grade $\mathrm{H}_{2}$ (mole fraction purity 0.999999) was obtained from the Neriki Gas Co., Ltd. The maximum impurity was $0.2 \mathrm{ppm}$ of nitrogen. Research grade $\mathrm{CO}_{2}$, ethane, cyclopropane, and propane (mole fraction purity 0.9999, 0.999, 0.995, and 0.9999, respectively) were obtained from the Takachiho Tradings Co., Ltd. The distilled water was obtained from the Wako Pure Chemicals Industries, Ltd. All of them were used without further purifications.

\section{EXPERIMENTAL PROCEDURE}

\section{Phase Equilibrium Measurements}

The gas mixture of $\mathrm{H}_{2}$ and hydrocarbon prepared at a desired composition was introduced into the evacuated highpressure cell. The content was pressurized up to the desired pressure by supplying water successively and then continuously agitated using the mixing bar. After the formation of gas hydrates, the system temperature was kept constant to establish the three-phase coexisting state of hydrate + aqueous solution + gas. The phase behavior was observed directly through the window. After reaching the equilibrium state of three-phase coexistence, a small amount of gas phase was sampled for composition analysis. The equilibrium composition of gas phase was analyzed for $\mathrm{H}_{2}$ and hydrocarbon by the TCD-Gas Chromatography (TCD-GC, Shimadzu GC$14 \mathrm{~B})$ as the water mole fraction of gas phase is negligible under the present experimental conditions.

\section{Raman Spectroscopic Analysis}

Under the three-phase equilibrium state, the single crystal of gas hydrates was analyzed through a quartz window by in situ Raman spectroscopy using a laser Raman microprobe spectrophotometer with multi-channel CCD detector. The argon ion laser beam (spot diameter: $2 \mu \mathrm{m}$, wavelength: $514.5 \mathrm{~nm}$, power: $100 \mathrm{~mW}$ ) from the object lens was irradiated to the sample through the upper quartz window. The backscatter of the opposite direction was taken in with the same lens. The spectral resolution was about $1 \mathrm{~cm}^{-1}$. All Raman spectra in hydrate phase are obtained from the hydrate single crystal that can be completely distinct from gas phase at microscopic field, under the three-phase equilibrium state (gas + aqueous solution + hydrate phases). In order to secure the laser focus on the hydrate crystal, Raman spectrum of $\mathrm{H}$ $\mathrm{H}$ vibration mode was measured simultaneously at the focal position where the characteristic spectra corresponding to the $\mathrm{CO}_{2}$ or hydrocarbon in hydrate crystal can be detected.

\section{THERMODYNAMIC ANALYSIS}

In the hydrocarbon + water binary system without $\mathrm{H}_{2}$, the fugacity of hydrocarbon in the gas phase can be evaluated at a given temperature as:

$f_{2}=\varphi_{2}\left(P_{2}^{\mathrm{e}}\right) P_{2}^{\mathrm{e}}$

where $f_{2}$ and $\varphi_{2}$ are the fugacity and fugacity coefficient of hydrocarbon at three-phase (gas + aqueous solution + hy- 
drate) equilibrium pressure $P_{2}^{\mathrm{e}}$, respectively. In the present study, the fugacity coefficient of pure hydrocarbon was calculated by use of Soave - Redlich - Kwong equation of state [19].

In the $\mathrm{H}_{2}+$ hydrocarbon + water ternary system, the equilibrium fugacity of hydrocarbon in the gas phase can be evaluated as:

$f_{2}=y_{2} \varphi_{2}\left(y_{2}, P^{\mathrm{e}}\right) P^{\mathrm{e}}$

where $y_{2}$ is equilibrium composition of hydrocarbon in the mixed gas phase and $P^{\mathrm{e}}$ stands for the three-phase (gas + aqueous solution + hydrate) equilibrium pressure.

Supposing that the generated gas hydrate is the pure hydrocarbon hydrate, that is, $\mathrm{H}_{2}$ is not enclathrated in hydrate cages, the fugacity of hydrocarbon calculated from equations (1) and (2) should coincide with each other. That is, the hydrocarbon hydrate cannot be generated until the fugacity of hydrocarbon in the gas mixture exceeds the equilibrium fugacity of pure hydrocarbon hydrate system.

The equation (3) is derived from equations (1) and (2).

$P^{\mathrm{e}}=\frac{\varphi_{2}\left(P_{2}^{\mathrm{e}}\right)}{\varphi_{2}\left(y_{2}, P^{\mathrm{e}}\right)} \frac{P_{2}^{\mathrm{e}}}{y_{2}}$

At a given gas-phase composition, the equilibrium pressure is obtained by the trial and error method from equation (3) on the assumption that the equilibrium fugacity of hydrocarbon in gas mixture is equal to that of pure hydrocarbon hydrate system in the whole composition range. The fugacity coefficient of hydrocarbon in the gas mixture was calculated by Soave - Redlich - Kwong equation of state [19] with the ordinary mixing rule (binary parameter $k_{12}=0.1867$ for $\mathrm{H}_{2}+$ ethane, 0.0 for $\mathrm{H}_{2}+$ cyclopropane, 0.2359 for $\mathrm{H}_{2}+$ propane) [20]. The applicable binary parameter for $\mathrm{H}_{2}+$ cyclopropane under the present experimental condition could not be found, therefore, the value of $k_{12}=0.0$ for $\mathrm{H}_{2}+$ cyclopropane is compelled to be used. The critical constants of hydrocarbon and $\mathrm{H}_{2}$ and other parameters were obtained from the reference [21].

\section{RESULTS AND DISCUSSION}

Reconfirmation of $\mathrm{H}_{2}$ Unoccupancy in the $\mathrm{CO}_{2}$ Hydrate by Raman Spectroscopy Using Quartz Windows

In order to reconfirm the cage unoccupancy of $\mathrm{H}_{2}$ in the $\mathrm{CO}_{2}$ hydrate, Raman spectra for single crystal of gas hydrates were measured at $276.5 \mathrm{~K}$. As mentioned above, the quartz windows were used instead of ordinary sapphire windows in the present study. In order to secure the laser focus on the hydrate crystal, Raman spectrum of $\mathrm{H}-\mathrm{H}$ vibration mode was measured simultaneously at the focal position where the characteristic spectra corresponding to $\mathrm{CO}_{2}$ in hydrate crystal can be detected. The Raman spectra obtained in the present study are shown in Fig. (2). As well as the results in our previous paper [14], Raman peaks of $\mathrm{H}-\mathrm{H}$ vibration are detected in only gas phase, while those of $\mathrm{CO}_{2}$ are detected in both gas and hydrate phases.

In addition to the Raman spectroscopic analysis, direct gas release method was performed. The hydrates prepared from $\mathrm{H}_{2}+\mathrm{CO}_{2}$ gas mixtures at $274.3 \mathrm{~K}$ were quenched and taken out from the high-pressure cell at $243 \mathrm{~K}$. After the dissociation of gas hydrate, gas sample was analyzed by use of the TCD-Gas chromatography. The mole fraction of $\mathrm{H}_{2}$ (water free) in hydrate phase is 0.007 at $274.3 \mathrm{~K}$ and $5.06 \mathrm{MPa}$. We conclude that $\mathrm{H}_{2}$ molecules adsorb on the hydrate surface rather than that $\mathrm{H}_{2}$ is enclathrated in hydrate cage. At the moment the reason for the discrepancy between our and other results [15] about the capability of $\mathrm{H}_{2}$ occupancy is unclear, but we speculate that the existence of aqueous phase (instead of ice solid phase) with hydrate phase may affect the $\mathrm{H}_{2}$ occupancy and that crystal lattice defects may be increased, caused by the difference between the preparation methods of hydrate sample (we have never prepared the hydrate samples from powder ice + gas mixtures).
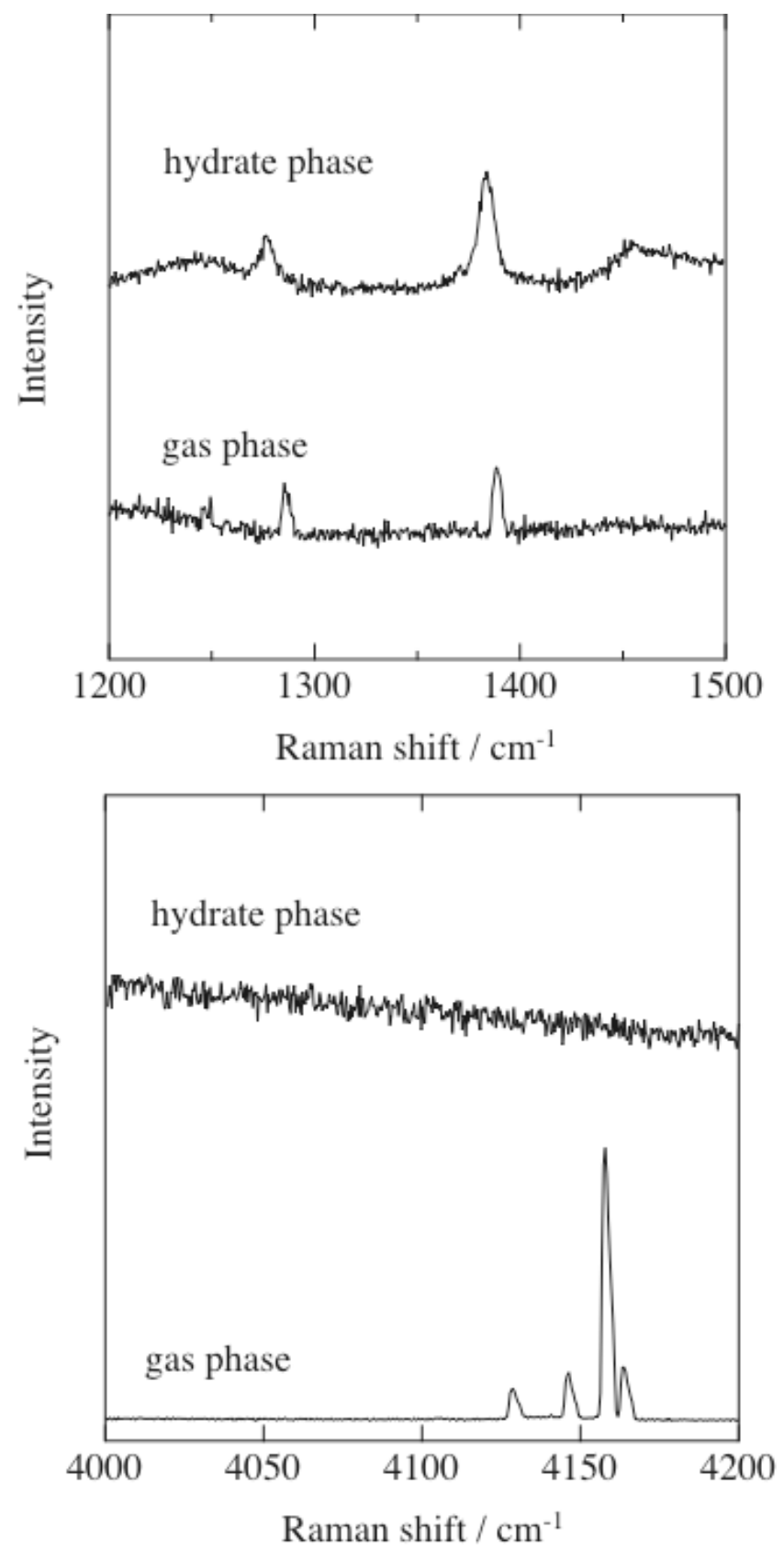

Fig. (2). Raman spectra in the gas and hydrate phases for the $\mathrm{H}_{2}+$ $\mathrm{CO}_{2}+$ water mixed system with quartz windows by use of $\mathrm{Ar}$ ion laser at $11.2 \mathrm{MPa}$ and $276.5 \mathrm{~K}$. Equilibrium mole fraction of $\mathrm{H}_{2}$ in gas phase $\left(y_{1}\right)$ is about 0.80 . 
Table 1. Phase Equilibrium Data for the $\mathbf{H}_{2}(1)+$ Hydrocarbon (2) + Water Mixed Systems in the Presence of Gas Hydrate at 276.1 K

\begin{tabular}{|c|c|c|}
\hline Systems & $p / \mathbf{M P a}$ & $y_{1}$ \\
\hline \multirow[t]{13}{*}{$\mathrm{H}_{2}+$ cyclopropane + water } & 0.11 & 0.0 \\
\hline & 0.16 & 0.33 \\
\hline & 0.18 & 0.48 \\
\hline & 0.21 & 0.58 \\
\hline & 0.23 & 0.60 \\
\hline & 0.26 & 0.65 \\
\hline & 0.27 & 0.67 \\
\hline & 0.28 & 0.68 \\
\hline & 0.31 & 0.69 \\
\hline & 0.33 & 0.71 \\
\hline & 0.50 & 0.80 \\
\hline & 0.71 & 0.84 \\
\hline & 1.18 & 0.90 \\
\hline \multirow[t]{12}{*}{$\mathrm{H}_{2}+$ ethane + water } & 0.67 & 0.0 \\
\hline & 0.75 & 0.11 \\
\hline & 0.82 & 0.20 \\
\hline & 1.03 & 0.39 \\
\hline & 1.55 & 0.54 \\
\hline & 1.55 & 0.57 \\
\hline & 1.70 & 0.58 \\
\hline & 2.08 & 0.67 \\
\hline & 2.50 & 0.73 \\
\hline & 2.91 & 0.78 \\
\hline & 3.32 & 0.79 \\
\hline & 4.44 & 0.83 \\
\hline \multirow[t]{20}{*}{$\mathrm{H}_{2}+$ propane + water } & 0.33 & 0.0 \\
\hline & 0.35 & 0.23 \\
\hline & 0.43 & 0.38 \\
\hline & 0.46 & 0.41 \\
\hline & 0.53 & 0.57 \\
\hline & 0.59 & 0.55 \\
\hline & 0.67 & 0.66 \\
\hline & 0.74 & 0.66 \\
\hline & 0.84 & 0.71 \\
\hline & 1.00 & 0.72 \\
\hline & 1.07 & 0.78 \\
\hline & 1.19 & 0.82 \\
\hline & 1.31 & 0.81 \\
\hline & 1.38 & 0.83 \\
\hline & 1.54 & 0.83 \\
\hline & 1.78 & 0.88 \\
\hline & 1.94 & 0.85 \\
\hline & 2.03 & 0.86 \\
\hline & 2.44 & 0.90 \\
\hline & 2.91 & 0.89 \\
\hline
\end{tabular}

Phase Equilibrium Measurements and Thermodynamic Analysis for $\mathrm{H}_{2}+\mathrm{Hydrocarbon}+$ Water Mixtures

The isothermal phase equilibrium data for three ternary systems of $\mathrm{H}_{2}+$ ethane + water, $\mathrm{H}_{2}+$ cyclopropane + water and $\mathrm{H}_{2}+$ propane + water obtained at $276.1 \mathrm{~K}$ are summarized in Table 1 and shown in Fig. (3). All three-phase equilibrium pressures increase monotonically with the increase of composition of $\mathrm{H}_{2}$. Each curve in Fig. (3) stands for the calculated values from equation (3) on the assumption that the equilibrium fugacity of each hydrocarbon in the gas mixture is equal to that of pure hydrocarbon hydrate system in the whole composition range.

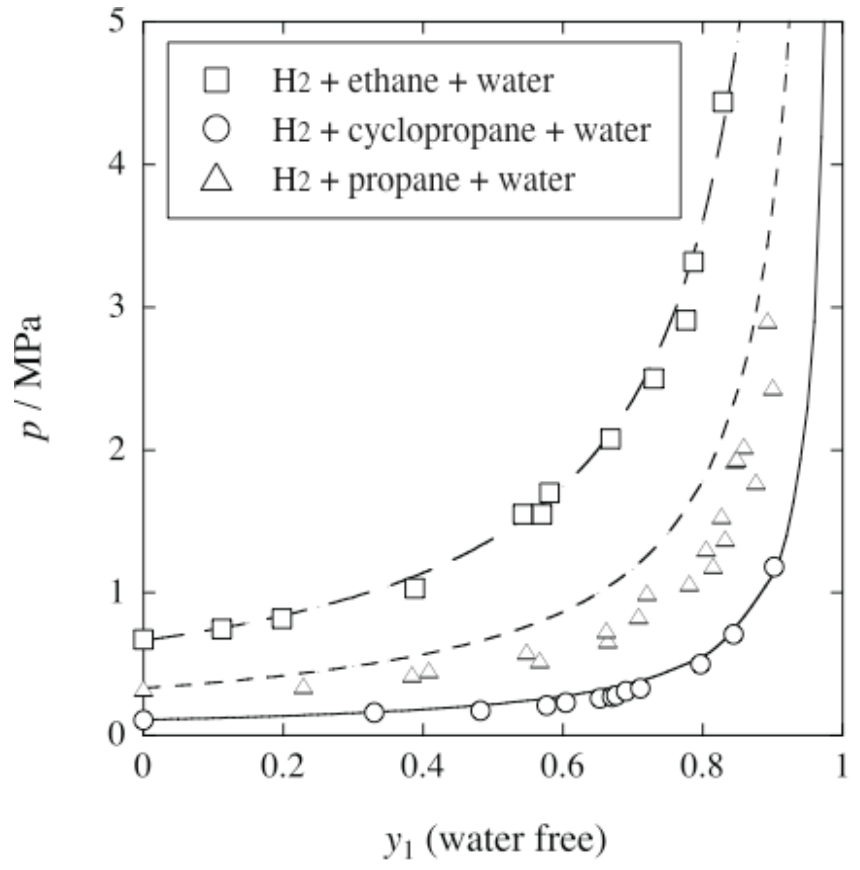

Fig. (3). Isothermal three-phase equilibrium (pressure-composition) relations for the $\mathrm{H}_{2}(1)+$ each hydrocarbon (2) + water mixed systems at $276.1 \mathrm{~K}$. The curves are estimated pressures by Eq. (3) on the assumption that the equilibrium fugacity of hydrocarbon in gas mixture is equal to that of pure hydrocarbon hydrate system in the whole composition range.

In both $\mathrm{H}_{2}+$ ethane + water and $\mathrm{H}_{2}+$ cyclopropane + water systems, the estimated pressures agree well with the experimental pressures as shown in Fig. (3). On the other hand, the experimental pressures shift to the hightemperature or low-pressure side of the estimated pressures in the $\mathrm{H}_{2}+$ propane + water mixed system. This indicates that the hydrate phase would be changed from the pure propane hydrate to the mixed propane one. In other words, there is a possibility that $\mathrm{H}_{2}$ can be enclathrated in the hydrate generated from $\mathrm{H}_{2}+$ propane + water mixture.

\section{Raman Spectroscopic Analysis for $\mathbf{H}_{2}+$ Hydrocarbon + Water Mixtures}

The Raman spectra obtained in the present study are shown in Figs. (4, 5, and 6). Fig. (4a) shows that the Raman peak corresponding to the intramolecular C-C stretching vibration mode of ethane is detected at $1000 \mathrm{~cm}^{-1}$ in the hydrate phase. The peak corresponding to the intramolecular C$\mathrm{C}$ stretching vibration mode of ethane in the M-cage of s-I hydrate is detected at $1000 \mathrm{~cm}^{-1}$ [22]. As shown in Fig. (5a), 
the Raman peak corresponding to the ring breathing mode of cyclopropane is detected at $1193 \mathrm{~cm}^{-1}$ in the hydrate phase, where it agrees well with that of the ring breathing vibration mode of cyclopropane in the M-cage of s-I hydrate [23]. As shown in Fig. (4b) and Fig. (5b), no peak of the intramolecular $\mathrm{H}-\mathrm{H}$ stretching vibration of $\mathrm{H}_{2}$ in the hydrate phase is detected in neither $\mathrm{H}_{2}+$ ethane + water nor $\mathrm{H}_{2}+$ cyclopropane + water systems (The peak should be detected around $4130 \mathrm{~cm}^{-1}$ if $\mathrm{H}_{2}$ is entrapped in the S-cage). Hence, the hydrates generated from these mixed systems are s-I hydrate originated in the pure ethane or cyclopropane hydrates and $\mathrm{H}_{2}$ cannot be entrapped with hydrate cages.
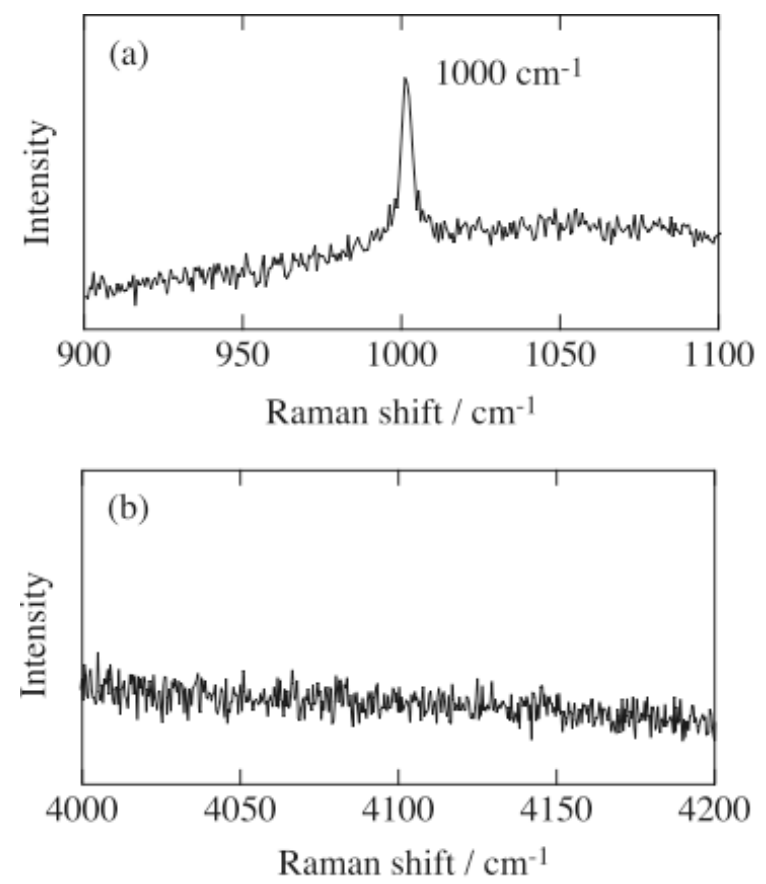

Fig. (4). Raman spectra of the intramolecular vibration for ethane around $1000 \mathrm{~cm}^{-1}$ (a), and around $4100 \mathrm{~cm}^{-1}$ (b) in the hydrate generated from the $\mathrm{H}_{2}(1)+$ ethane (2) + water mixed system at 1.95 MPa, $y_{1}=0.62$, and $276.1 \mathrm{~K}$.

Fig. (6a) shows that the Raman peak corresponding to intramolecular C-C stretching vibration mode of propane is detected at $877 \mathrm{~cm}^{-1}$ in the hydrate phase. It is known that the peak corresponding to the $\mathrm{C}-\mathrm{C}$ stretching vibration mode of propane in the large cage (L-cage) of s-II hydrate is detected at $877 \mathrm{~cm}^{-1}$ [24]. Fig. (6a) also shows that the Raman peak derived from the $\mathrm{H}_{2}$ rotation is detected around $581 \mathrm{~cm}^{-1}$ in the hydrate phase, which is the strongest peak corresponding to the $\mathrm{H}_{2}$ rotation [25]. The peak derived from the $\mathrm{H}-\mathrm{H}$ stretching vibration of $\mathrm{H}_{2}$ is detected around $4131 \mathrm{~cm}^{-1}$ in the hydrate phase as shown in Fig. (6b). This Raman shift agrees with that of $\mathrm{H}_{2}$ encaged in the S-cage of s-II hydrate $[6,7]$. That is, $\mathrm{H}_{2}$ can selectively occupy the S-cage of s-II hydrate generated from $\mathrm{H}_{2}+$ propane + water mixture, while propane occupies the L-cage entirely.

The hydrates prepared from gas mixtures at $276.1 \mathrm{~K}$ were quenched and taken out from the high-pressure cell at $243 \mathrm{~K}$. After the dissociation of gas hydrate, gas sample was analyzed by use of the TCD-Gas chromatography. The mole fractions of $\mathrm{H}_{2}$ (water free) in the dissociation gas of the hydrate generated from $\mathrm{H}_{2}+$ propane gas mixtures, in which the Raman peaks of $\mathrm{H}_{2}$ are detected, is about 0.1 at $0.8 \mathrm{MPa}$ and about 0.2 at $1.5 \mathrm{MPa}$. About five and ten percent of Scages in the s-II hydrate are occupied by $\mathrm{H}_{2}$ molecule at such mild condition, respectively. In the other systems of no Raman peak of $\mathrm{H}_{2}$, the mole fraction (water free) of $\mathrm{H}_{2}$ in the dissociation gas is less than 0.001 .
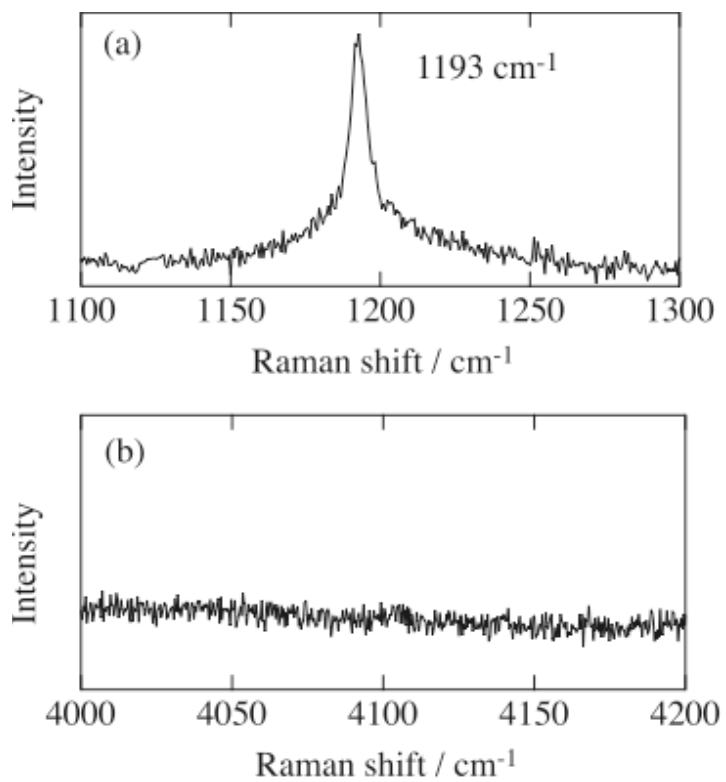

Fig. (5). Raman spectra of the intramolecular vibration for cyclopropane (a), and around $4100 \mathrm{~cm}^{-1}$ (b) in the hydrate generated from the $\mathrm{H}_{2}(1)+$ cyclopropane $(2)+$ water mixed system at 0.403 $\mathrm{MPa}, y_{1}=0.71$, and $276.1 \mathrm{~K}$.
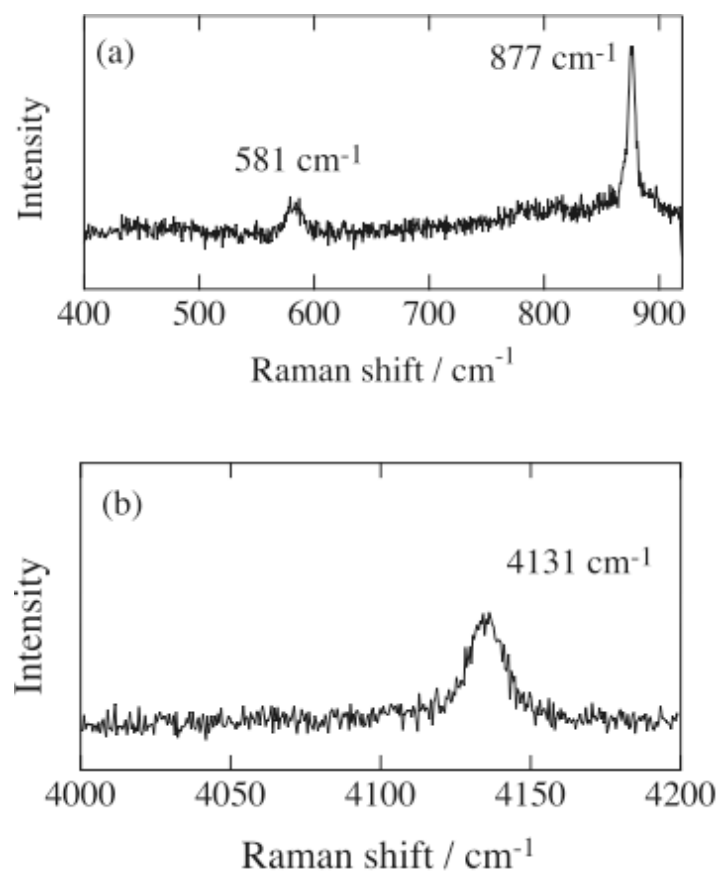

Fig. (6). Raman spectra of the intramolecular vibration for propane around $870 \mathrm{~cm}^{-1}(\mathbf{a})$, and $\mathrm{H}_{2}$ (around $4150 \mathrm{~cm}^{-1}$ ) (b) in the hydrate phase for the $\mathrm{H}_{2}(1)+$ propane (2) + water mixture at $1.50 \mathrm{MPa}, y_{1}$ $=0.82$, and $276.1 \mathrm{~K}$. Panel (a) contains the Raman peak of $581 \mathrm{~cm}^{-1}$ corresponding to the rotation of $\mathrm{H}_{2}$.

In the present study, the occupation of $\mathrm{H}_{2}$ in the hydrate generated from $\mathrm{H}_{2}+$ propane + water mixture has been confirmed by use of Raman spectroscopic analyses. The cage occupancy of $\mathrm{H}_{2}$ in various mixed systems at relatively low- 
pressure condition (up to $2 \mathrm{MPa}$ ) is summarized in Table 2. The $\mathrm{H}_{2}$ molecule can occupy the $\mathrm{S}$-cage of s-II hydrate even at a few MPa, while it cannot occupy that of s-I hydrate at similar conditions. In the cases of ethane or cyclopropane additive, $\mathrm{H}_{2}$ cannot be enclathrated in the hydrate despite the existence of empty S-cages. The S-cage of s-II is somewhat smaller than that of s-I [26], which may cause the variation of $\mathrm{H}_{2}$ occupation depending on the difference between s-I and s-II.

Table 2. S-Cage Occupancy of $\mathrm{H}_{2}$ at $276.1 \mathrm{~K}$ and up to 2 MPa. The Data $\mathrm{CH}_{4}$, and THF were Obtained from the References $[6,18]$, Respectively

\begin{tabular}{|c|c|c|}
\hline Additives & Hydrate Structure & S-Cage Occupancy of $\mathbf{H}_{\mathbf{2}}$ \\
\hline \hline $\mathrm{CO}_{2}$ & $\mathrm{I}$ & - \\
\hline $\mathrm{CH}_{4}[18]$ & $\mathrm{I}$ & - \\
\hline ethane & $\mathrm{I}$ & - \\
\hline cyclopropane & $\mathrm{I}$ & - \\
\hline propane & $\mathrm{II}$ & occupied \\
\hline THF [6] & $\mathrm{II}$ & occupied \\
\hline
\end{tabular}

\section{CONCLUSIONS}

Isothermal phase equilibria for three hydrogen + hydrocarbon + water mixed systems containing gas hydrates were measured at $276.1 \mathrm{~K}$. The present findings from phase equilibrium analysis and Raman spectroscopic study suggest that the hydrogen generates the mixed gas hydrate in the presence of propane. $\mathrm{CO}_{2}$, ethane and cyclopropane do not play a role as the guest species of mixed gas hydrate containing hydrogen.

\section{ACKNOWLEDGMENT}

This work was financially supported by New Energy Industrial Technology Development Organization (NEDO). S. H. shows his gratitude for the center of excellence (COE) program of Osaka University. This work was partially supported by the Ministry of Education, Culture, Sports, Science and Technology (MEXT), Grant-in-Aid for Young Scientists (B)(19760491). We gratefully acknowledge the Division of Chemical Engineering, Graduate School of Engineering Science, Osaka University for the scientific support by "GasHydrate Analyzing System (GHAS)".

\section{REFERENCES}

[1] Y. A. Dyadin, E. G. Larionov, E. Y. Aladko, A. Y. Manakov, F. V. Zhurko, T. V. Mikina, V. Y. Komarov, and E. V. Grachev, "Clathrate Formation in Water-Noble Gas (Hydrogen) Systems at High Pressures", J. Struct. Chem., vol. 40, pp. 790-795, Sep. 1999

[2] W. L. Mao, H. Mao, A. F. Goncharov, V. V. Struzhkin, Q. Guo, J. Hu, J. Shu, R. J. Hemley, M. Somayazulu, and Y. Zhao, "Hydrogen Clusters in Clathrate Hydrate", Science, vol. 297, pp. 2247-2249, Sep. 2002.

[3] L. J. Florusse, C. J. Peters, J. Schoonman, K. C. Hester, C. A. Koh, S. F. Dec, K. N. Marsh, and E. D. Sloan, "Stable Low-Pressure Hydrogen Clusters Stored in a Binary Clathrate Hydrate", Science, vol. 306, pp. 469-471, Oct. 2004.
[4] H. Lee, J. -W. Lee, D. Y. Kim, J. Park, Y. -T. Seo, H. Zeng, I. L. Moudrakovski, C. I. Ratcliffe, and J. A. Ripmeester, "Tuning Clathrate Hydrates for Hydrogen Storage", Nature, vol. 434, pp. 743-746, Apr. 2005.

[5] T. A. Strobel, C. J. Taylor, K. C. Hester, S. F. Dec, C. A. Koh, K. T. Miller, and E. D. Sloan, Jr., "Molecular Hydrogen Storage in Binary THF-H ${ }_{2}$ Clathrate Hydrates", J. Phys. Chem. B, vol. 110, pp. 17121-17125, Aug. 2006.

[6] S. Hashimoto, S. Murayama, T. Sugahara, H. Sato, and K. Ohgaki, "Thermodynamic and Raman Spectroscopic Studies on $\mathrm{H}_{2}+$ Tetrahydrofuran + Water and $\mathrm{H}_{2}+$ Tetra- $n$-Butyl Ammonium Bromide + Water Mixtures Containing Gas Hydrates", Chem. Eng. Sci., vol. 61, pp. 7884-7888, Dec. 2006.

[7] S. Hashimoto, T. Sugahara, H. Sato, and K. Ohgaki, "Thermodynamic of $\mathrm{H}_{2}+$ Tetrahydrofuran Mixed Gas Hydrate in Nonstoichiometric Aqueous Solutions", J. Chem. Eng. Data, vol. 52, pp. 517-520, Mar. 2007.

[8] R. Anderson, A. Chapoy, and B. Tohidi, "Phase Relation and Binary Clathrate Hydrate Formation in the System $\mathrm{H}_{2}-\mathrm{THF}-\mathrm{H}_{2} \mathrm{O}$ ", Langmuir, vol. 23, pp. 3440-3444, Mar. 2007.

[9] S. Hashimoto, T. Sugahara, M. Moritoki, H. Sato, and K. Ohgaki, "Thermodynamic Stability of Hydrogen + Tetra- $n$-Butyl Ammonium Bromide Mixed Gas Hydrate in Nonstoichiometric Aqueous Solutions", Chem. Eng. Sci., vol. 63, pp. 1092-1097, Feb. 2008.

[10] T. A. Strobel, C. A. Koh, and E. D. Sloan, "Hydrogen Storage Properties of Clathrate Hydrate Materials", Fluid Phase Equilibria, vol. 261, pp. 382-389, Dec. 2007.

[11] A. Chapoy, R. Anderson, and B. Tohidi, "Low-Pressure Molecular Hydrogen Storage in Semi-Clathrate Hydrates of Quaternary Ammonium Compounds", J. Am. Chem. Soc., vol. 129, pp. 746-747, Jan. 2007.

[12] S. Choi, K. Shin, and H. Lee, "Structure Transition and Tuning Pattern in the Double (Tetramethylammonium Hydroxide + Gaseous Guests) Clathrate Hydrates", J. Phys. Chem. B, vol. 111, pp. 10224-10230, Aug. 2007.

[13] T.A. Strobel, K. C. Hester, E. D. Sloan, Jr., and C. A. Koh, "A Hydrogen Clathrate Hydrate with Cyclohexanone: Structure and Stability", J. Am. Chem. Soc., vol. 129, pp. 9544-9555, Aug. 2007.

[14] T. Sugahara, S. Murayama, S. Hashimoto, and K. Ohgaki, "Phase Equilibria for $\mathrm{H}_{2}+\mathrm{CO}_{2}+\mathrm{H}_{2} \mathrm{O}$ System Containing Gas Hydrates", Fluid Phase Equilibria, vol. 233, pp. 190-193, Jun. 2005.

[15] D.-Y. Kim, and H. Lee, "Spectroscopic Identification of the Mixed Hydrogen and Carbon Dioxide Clathrate Hydrate", J. Am. Chem. Soc., vol. 127, pp. 9996-9997, Jul. 2005.

[16] S. -X. Zhang, G. -J. Chen, C. -F. Ma, L. -Y. Yang, and T. -M. Guo, "Hydrate Formation of Hydrogen + Hydrocarbon Gas Mixtures", $J$. Chem. Eng. Data, vol. 45, pp. 908-911, Sep. 2000.

[17] J. B., Klauda, and S. I. Sandler, "Phase Behavior of Clathrate Hydrates: A Model for Single and Multiple Gas Component Hydrates", Chem. Eng. Sci., vol. 58, pp. 27-41, Jan. 2003.

[18] S. S. Skiba, E. G. Larionov, A. Y. Manakov, B. A. Kolesov, V. I. Kosyakov, "Investigation of Hydrate Formation in the System $\mathrm{H}_{2-}$ $\mathrm{CH}_{4}-\mathrm{H}_{2} \mathrm{O}$ at a Pressure up to $250 \mathrm{MPa}$ ", J. Phys. Chem. B, vol. 111, pp. 11214-11220, Sep. 2007.

[19] G. Soave, "Equilibrium Constants from a Modified Redlich Kwong Equation of State", Chem. Eng. Sci., vol. 27, pp. 11971203, Jun. 1972.

[20] H. Knapp, R. Doring, L. Oellrich, U. Plocker, J. M. Prausnitz, Vapor - Liquid Equilibria for Mixtures of Low Boiling Substances, Chemistry Data Series, vol. VI, Dechema: Frankfurt, 1982.

[21] R. C. Reid, J. M. Prausnitz, and B. E. Poling, The Properties of Gases and Liquids, 4th ed., New York: McGraw-Hill, 1986.

[22] K. Morita, S. Nakano, and K. Ohgaki, "Structure and Stability of Ethane Hydrate Crystal", Fluid Phase Equilibria, vol. 169, pp. 167175, Mar. 2000.

[23] M. Suzuki, Y. Tanaka, T. Sugahara, and K. Ohgaki, "Pressure Dependence of Small-Cage Occupancy in the Cyclopropane Hydrate System", Chem. Eng. Sci., vol. 56, pp. 2063-2067, Mar. 2001.

[24] A. K. Sum, R. C. Burruss, E. D. Sloan, Jr., "Measurement of Clathrate Hydrates via Raman Spectroscopy", J. Phys. Chem. B, vol. 101, pp. 7371-7377, Sep. 1997.

[25] U. Fink, T. A. Wiggins, and D. H. Rank, "Frequency and Intensity Measurements on the Quadruple Spectrum of Molecular Hydrogen", J. Mol. Spectro., vol. 18, pp. 384-395, Dec. 1965.

[26] S. Subramanian, and E. D. Sloan, Jr., "Trends in Vibrational Frequencies of Guests Trapped in Clathrate Hydrate Cages", J. Phys. Chem. B, vol. 106, pp. 4348-4355, May 2002. 